\title{
NonlinearModel Calibration of a Shear Wall Building using Time and Frequency Data Features
}

\author{
Eliyar Asgarieh $^{\mathrm{a}}$, Babak Moaveni ${ }^{\mathrm{a}^{*}}$, Andre R. Barbosa $^{\mathrm{b}}$, and Eleni Chatzi ${ }^{\mathrm{c}}$ \\ ${ }^{a}$ Dept. of Civil and Environmental Engineering, Tufts University, Medford, Massachusetts, USA \\ ${ }^{b}$ School of Civil and Construction Engineering, Oregon State University, Corvallis, Oregon, USA \\ ${ }^{c}$ Dept. of Civil, Environmental and Geomatic Engineering, Swiss Federal Institute of Technology (ETH), \\ Zurich, Switzerland
}

\begin{abstract}
This paper investigates the effects of different factors on the performance of nonlinear model updating for a seven-story shear wall building model. The accuracy of calibrated models using different data features and modeling assumptions is studied by comparing the time and frequency responses of the models with the exact simulated ones.Simplified nonlinear finite element models of the shear wall building are calibrated so that the misfit between the considered response data features of the models and the structure is minimized. A refined FE model of the test structure, which was calibrated manually to match the shake table test data of the structure, is used instead of the real structure for this performance evaluation study. The simplified parsimonious FE models are composed of simple nonlinear beam-column fiber elements with nonlinearity infused in them by assigning generated hysteretic nonlinear material behaviors to uniaxial stress-strain relationship of the fibers.Four different types of data features and their combinations are usedfor model calibration: (1) time-varying instantaneous modal parameters, (2) displacement time histories, (3) acceleration time histories, and (4) dissipated hysteretic energy. It has been observed that the calibrated simplified FE models can accurately predict the nonlinear structural response in the absence of significant modeling errors. In the last part of this study, the physics-based models are further simplified for casting into state-space formulation and a real-time identification is performed using an Unscented Kalman filter. It has been shown that the performance of calibratedstate-space models can be satisfactory when reasonable modeling assumptions are used.
\end{abstract}

Keywords: Nonlinear structural identification, FE model updating, time-varying instantaneous modal parameters, Unscented Kalman filter

\section{Introduction}

A large number of methods exist in the literature for identification of structural systems from measured dynamic data. Among these methods, finite element (FE) model updating has received increased attention in the structural health monitoring research community with the goal of reliable response prediction and performance assessment of civil structures. Physics-based FE modelscan directly use the available information from geometry and material behavior of a

\footnotetext{
${ }^{*}$ Corresponding author; Mailing address: Dept. of Civil and Environmental Engineering, 200 College Ave., Medford, Massachusetts 02155, USA; Telephone: +1 617627 5642; Fax: +1 617627 3994; E-mail: babak.moaveni@tufts.edu
} 
structural system and therefore can mitigate the effects of modeling error and uncertainty in the identification process [1-4]. Most of the FE model updating studies in the literature are restrictedto linear model assumption $[5,6]$. In the application of linear model updating, selected model parameters are tuned to match the extracted data features measured during the linear (lowamplitude)response of structures. Comparison of linear modeling parameters (often stiffness) before and after a damaging event,such as an earthquake, can be used for estimating the location and extent of damage in the structure. Successful application of linear FE model updating can be found in the literature for damage identification [7-12]. However, updated linear models are only useful for predicting the future response of structures to low amplitude excitations, and can lead to large errors when used for nonlinear response estimation [13, 14]. In addition, most civil structures areinherently characterized by nonlinear behavior and therefore in an effort toavoid large modeling errors, nonlinearity should be taken into consideration [15]. To this end, nonlinear models are necessaryfor accurate and efficient prediction of structural response to moderate-to-high amplitude excitations.

The nonlinearity in FE models of civil engineering structures isoften modeled via assignment ofappropriate hysteretic materialpropertiesto groups or clusters of elements. Therefore, for calibration of such nonlinear FE models, it would suffice to estimate the time-invariant parameters of the hysteretic constitutive law, rendering such a formulation particularly convenient for model updating purposes. Few applications of nonlinear FE model updating exist in the literature [16-20]. The accuracy of calibrated nonlinear models gravely depends on the choice of data features used in the updating process and modeling assumptions. In this paper, the effects of four types of data features in the updating process are investigated. In addition, some of the common difficulties of updating nonlinear models of complex systems such as illconditioning and lack of identifiability arestudied. The role of modeling error/uncertainty is also studied on the accuracy of identification results by considering models with different constraints and hysteretic material behaviors. The case study analysis is performed on the simulated response of a seven-story shear wall building using a detailed FE model of the test structure, which was calibrated manually to match the recorded test data. Nonlinear FE models of the structure are calibrated by minimizing an objective function defined as a measure of the discrepancybetween data features of the forward simulation models and their simulated counterparts using the simulated annealing (SA) global optimization method [21].

In the case of using non-physics based models, several methods exist in the literature for nonlinear model calibration. Among these methods, adaptive methods such as Kalman or Particle filters have been used successfully for real-time nonlinear identification [22-30]. In these applications, nonlinearity is modeled using analytical phenomenological material models such as the Bouc-Wenmodel [31-34]. Although this framework has been applied successfully in many cases and promising results are reported, its applicability is hindered by problems such as large modeling errors inthe considered state-space models (such as oversimplification of models, wrong boundary conditions and constraint assumptions, and incompatible nonlinear models) and difficulty of applying these models to more complex structural systems with large number of degrees-of-freedom[35]. In this paper, the applicability of an Unscented Kalman filter [36, 37] algorithm is demonstrated for identifying two nonlinear state-space models of the test structure relying ondifferent modeling assumptions. The effects of these modeling assumptions on the performance of the implemented Kalman filter are investigated. 
The work presented herein is formulated as follows. Section 2 briefly describes the test structure, the detailed FE models used for response simulation, and the simplified FE models applied for identification. Section 3 presents the model updating process, the updating results, and the performance of the applied models for structural identification. In Section 4, simplified statespace models are identified by the Unscented Kalman filter and it is shown that more realistic modeling assumptions can significantly improve the accuracy of the real-time identification. Finally, in Section 5 the major points of this research are highlighted and conclusions are drawn.

\section{Test Structure and FE Models}

\subsection{Detailed FE Model Used for Simulating the "Measured Data"}

The test structure was a full scale seven-story reinforced concrete shear wall building section (Figure 1a), and consisted of a web wall as the resisting mechanism against lateral loads, a flange wall for transverse stability, a post-tensioned column that provided torsional stability, and four gravity columns for supporting the weight of the floor slabs. The structurewas tested on the shake table of the University of California at San Diego (UCSD) in 2006 through base excitations of increasing intensities. More details about the structure and dynamic tests can be found in [38]. In this paper, theresponse of the test structure to be used in identification isnumerically simulated using a refined nonlinear FE model of it. The nonlinear FE model (Figure 1b, Figure 2) was developed in OpenSees [39] - based on the knowledge from the geometry and material properties of the test structure - and was calibrated manually to represent the measured response of the test structure to a large earthquake shake table excitation. The FE model consists of 509 nodes, 198 elastic beam-column elements, 35 nonlinear beam-column elements with fiber cross-sections, and 315 linear elastic shell elements. The nonlinearity is defined as uniaxial stress-strain relations at fiber cross-sections in nonlinear beam-column elements, using Giuffre-Menegotto-Pinto [40] and Popovics [41] material models for simulating the nonlinear behavior of reinforcing steel bars and concrete, respectively. In the FE model, the web walls are modeled using four beam-column elements connected in series per story, and each beam-column fiber element is discretized into four fiber-sections (connected through GaussLobatto integration points) each containing multiple uniaxial fibers. The flange walls are modeled by a single beam-column element per story, in which four integration points are defined for each element. To improve the efficiency of the FE model, other parts of the structure are assumed to have linear elastic behavior and are modeled using elastic beam-column elements and linear elastic shell elements.A 2.5\% Rayleigh damping ratio is considered at the first and second translational modal frequencies of the model.

The response of the system is simulated for one of the shake table excitation tests. The selected input earthquake acceleration is the longitudinal component from the Woodland Hills Oxnard Boulevard (WHOX) station recorded during the 1994 Northridge earthquake (Figure 1c). It should be mentioned that the record used as input in the simulations was not the earthquake ground motion record itself, but instead the recorded acceleration time history on top of the shake table was applied.The sampling frequency of the "measured" data is considered the same as the sampling frequency during the test, which was $240 \mathrm{~Hz}$.

\subsection{Simplified FE Models Used in Identification}

Simplified FE models, which are significantly different from the detailed model, are used in the identification process. The simplified or approximatemodeling alternatives introduce 
modeling errors into the identification process, a consequence which is inevitable for real-world applications and complex civil structures. Modeling errors are also introduced due to the system's discretization and the numerical integration schemes involved. The simplified FE models consist of lumped masses connected to each other with beam-column fiber-section elements, with or without constraints atthe rotationaldegrees-of-freedom (DOFs), i.e.,shear building or cantilever models, respectively. Additionally, in the identification processfour different hysteretic material models areattributed to the fiber sectionsfor studying the effects of different material behavior assumptions. Based on a-priori knowledge from the structure and its material properties, different nonlinear material model classes can be considered in the FE model. The types of material models considered in this study consist ofthree physics-based parallel hysteretic models for reinforced concrete and the Bouc-Wen model that is flexible enough formodeling different material behaviors. Figure 3 briefly describes the simplified nonlinear FE models and the process of generating the three physics-based hysteretic models. In this process, three different material models for concrete and one for steel are selected and combined in parallel to find the most suitable material modelrepresenting the simulated nonlinear response of the structure. Three commonly applied hysteretic models for concrete materials, which are themodels suggested by Popovics [41], Kent-Scott-Park [42], and Yassin [43] are placed in parallel with the steel material model proposed by Giuffre-Menegotto-Pinto [40] for generating three physics-based mechanical material models that have hysteretic behaviors similar to the reinforced concretesections. The fourth applied material model is the Bouc-Wen model[31-34], which is an analytical phenomenological model whose structure is particularly convenient for state-space identification implementations. The latter is particularly important for coupling this model with a Kalman Filter based identification approach.Each of the four material models is assigned to the fiber sections at nonlinear beam-column elements to define the uniaxial stress-strain relation in the fibers.

The sections in nonlinear beam-column elements of the simplified models are discretized into 25 fibers with fivefibers in each direction, which are connected by five integration points along each element. The lumped masses in the model are estimated from the structure and are assigned at the nodes, the heights of the stories are also the same as the real test structure, and the hysteretic material models are chosen based on the knowledge from the material type. The model was designed to be very simple, and use minimal information about the geometry (height of stories and boundary conditions) and material properties of the structure. These simplified models are efficient for generally time consuming global optimizations in the updating process, and also can be related to equivalent state-space models that are used by adaptive methods such as Kalman filters.

\section{Nonlinear Model Updating}

This section reviews the process of updating the model parameters given the measured data. Parameters of considered material models in the simplified FE models are calibrated so that the discrepancybetween selected response features of the model and their measured counterpartsis minimized.The elements of the simplified FE models are divided into substructures with similar material properties. Three substructures are considered for the simple FE models, namely the first story element, the second story element, and upper story elements as shown in Figure 3(a). The updating process is performed in two steps; firstthe initial linear stiffness of the material models in each substructureis calibrated by matching the first three translational modal parameters of the models to the measured (simulated) values at the beginning of the excitation with lower 
amplitude of excitation. The structure is assumed to behave linearly during the low amplitude part of the excitation. Inthe second step, the parameters of the hysteretic material models are calibrated by minimizing a suitably formulated objective function. The objective function, presented in Equation 1, is defined as the weighted sum of the squared response residuals (data features differences)and is minimized using the SA global optimization method.

$$
G(\boldsymbol{\theta})=\sum_{t=1}^{N_{t}} g_{t}(\boldsymbol{\theta})=\sum_{t=1}^{N_{t}} \mathbf{r}_{t}(\boldsymbol{\theta})^{T} \mathbf{W}_{t} \mathbf{r}_{t}(\boldsymbol{\theta})
$$

In Equation 1, $\theta$ represents the parameters of the model to be identified, $\mathbf{r}_{t}$ is the calculated residual vector at time $t, \mathbf{W}_{t}$ is the diagonal weight matrix that is assumed to be equal to the identity matrix in this research (i.e., different residuals at different time instances have the same importance), and $N_{\mathrm{t}}$ is the number of considered time instances during which the residuals are calculated. This study investigates the effects of two factors on the performance of model calibration process. The first factor considers different constraint assumptions (cantilever versus shear building model) and material behavior (Popovic-Pinto, Kent-Pinto, Yassin-Pinto, and Bouc-Wen) in the models. The second factor considers use of different residuals in the objective function in an effort to investigate the dependency of the model updating scheme on the optimization problem formulation. Four types of data features are considered in the residuals,includingtime-varying modal parameters, displacements, accelerations, and dissipated hysteretic energy. Overall sixteen different residual vectors are used in the updating process based on different combination of the mentioned data features.

The first three parallel material models usethe same hysteretic model for steel but different models for concrete with similar parameterization and backbone curves. Figure 4 plots the stressstrain (backbone) curves of the Popovic material model for concrete and Giuffre-MenegottoPinto model for steel with their parameters. The combination of these two models makes the first parallel material model. In this figure, $\mathrm{F}_{\mathrm{y}}$ and $\mathrm{b}$ define the yield stress and post-to-initial stiffness ratio of the steel material model, while $\sigma_{\mathrm{c}}$ is the maximum strength, and $\varepsilon_{\mathrm{c}}$ and $\varepsilon_{\mathrm{cu}}$ indicate the strain at the maximum strength and crushing pointsof the concrete material,respectively. In order to prevent negative stiffness at the softening branchof the model at extreme nonlinearities, $\varepsilon_{\mathrm{c}}$ and $\varepsilon_{\mathrm{cu}}$ are assumed to be equal. This prevents havingcomplex(with non-zero imaginary component) eigenvalues in extreme nonlinearities which causes problem in the optimization process. The estimated values of $\varepsilon_{\mathrm{c}}=\varepsilon_{\mathrm{cu}}$ for this material model are relatively large which prevent brittle failure of the fibers. The parameter $\alpha$ in all three parallel material modelsdescribes the share of each of the steel and concrete models of the total initial stiffness. It is worth noting that the degradation of stiffness for unloading and reloading of concrete in Popovics (Model 1) and Kent (Model 2) models follow the work of Karsan and Jirsa [44]. However, the ratio between the unloading and initial slopes of the stress-strain curve in the Yassin model (Model 3) is defined by parameter " $\lambda$ ", which is not considered as an updating parameter and a value of $\lambda=0.1$ is adopted in this study. The fourth material model is considered as an extended Bouc-Wen model [32] without including the effects of pinching or strength degradation. Equation 2 represents the formulation of the implemented Bouc-Wen model. 
$R(x, z)=\alpha K_{0} x+(1-\alpha) K_{0} z$

$\dot{z}=\frac{1}{\eta}\left[A \dot{x}-\beta|\dot{x}||z|^{n-1} z-\gamma \dot{x}|z|^{n}\right]$

$\eta(\varepsilon)=1+\delta_{\eta} \varepsilon$

This model can be fully parameterized by 7 parameters, $K_{0}, A, \alpha, \beta, \gamma, n$, and $\delta_{\eta}$. In this equation, $x$ is the displacement response and $z$ is the hysteretic displacement response of the system. $R$ represents the nonlinear restoring force, $K_{0}$ identifies the initial linear stiffness of the element, and $\alpha$ defines the share of linear restoring force while $(1-\alpha)$ denotes the share of virtual hysteretic force. $\gamma$ and $\beta$ define the shape of the hysteretic loop, and $\eta$ is the stiffness degradation parameter. The intensity of the stiffness degradation is determined by $\delta_{\eta}$ coefficient multiplied by the accumulated dissipated hysteretic energy $\varepsilon$. Based on the authors' past experience [45] and the sensitivity of the nonlinear response to different parameters of the Bouc-Wen model [33, 34], four parameters of the model will be calibrated in this study, namely $K_{0}, \alpha, \beta$, and $\delta_{\eta}$. Values of the remaining three parameters are selected as $A=1, n=1$, and $\gamma=\beta$.The number of updating parameters in the model updating process depends on the considered material models in each substructure and the number of substructures. Table 1 represents the considered updating parameters for each of the four material models. Based on this table and the fact that the FE model is discretized into three substructures, the total number of updating parameters in the second step of model calibration is $15,15,15$, and 9 for material models 1 to 4 , respectively.

The second factor that can influence the accuracy and performance of the model updating procedure is the choice of residuals in the objective function. In this study, the model updating results are cross evaluated on the basis of sixteen different residuals. These residuals are based on different data features and their combinations. In general, the features that are directly measured (e.g., acceleration) contain the least amount of error. However, they may not be the best features to be used for model calibration. This can be due to low sensitivity of updating parameters to these features or the importance of the features in damage assessment of the underlying structural system. In addition, calibrating models with some specific features may result in a more consistent match between model and structure even in the features that are not used for model calibration. Figure 5 shows the considered types of response features measured (simulated) during the 1994 Northridge earthquake for the considered seven-story shear wall structure. It includes the acceleration and displacement response time histories, the estimated cumulative base shear versus first story displacement hysteretic energy, and the identified timevarying natural frequencies of the first three longitudinal modes at 25 time instances. It should be noted that the base shear is approximately estimated using only the total horizontal accelerations at floor levels. The identified time-varying natural frequencies are the average of exact instantaneous modal frequencies from the detailed FE model over a window of 0.5 second around the selected points. In experimental applications, the time-varying modal parameters can be identified using a windowed deterministic-stochastic subspace identification (DSI) method $[46,47]$. The considered time instances are arbitrarily selected along the response and correspond to the local peaks in the displacement time history. It has been observed by the authors that the local peaks are moreinformative about the nonlinear behavior of the structure, and therefore can yield accurate identification results. 
Table 2 presents the 16 considered residuals in this study and the data features used in each residual. The first residual is based on the identified natural frequencies and mode shapes (with seven components at floor levels) of the first three translational modes shown in Figure 1 at 25 time instances. To study the effect of number of time instances (points) considered in the acceleration, displacement, or hysteretic energy time histories, two different lengths of residual vectors are used for each of these residuals, namely 25 (same instances considered for timevarying modal parameters) or 50 seconds $\times 240 \mathrm{~Hz}=12,000$ points of response measurements.It should be mentioned that the acceleration, displacement, and energy features include measurements at all seven floor levels.Since the estimated hysteretic plots are very erratic, especially during the moments with more intense excitation and higher nonlinear behavior, filtering can help for better comparison between the identified and model simulated values. The hysteretic energy time histories have been filtered using a low-pass FIR filter of order 100 with the cut-off frequency of $48 \mathrm{~Hz}$. The order of the filter and its cut-off frequency are chosen subjectively. The filter removes the high frequency noise in the estimated hysteretic energy plot, which is owed to accumulation of error in numerical computations.

\subsection{Step 1: Calibration of Linear Model Parameters}

In this step, the parameters of the underlying linear models (i.e., the elastic stiffness components of three substructures) are calibratedby matching the natural frequencies and mode shapes of the first three translationalmodes at the beginning of the excitation. The structure is assumed to behave linearly during the low amplitude part of response near the beginning of excitation (the first three seconds)and therefore the modal parameters are time-invariant. Larger weights (10 times) areassigned to the natural frequency residualscompared to the mode shape residuals, due to the larger number of mode shape components and the higher sensitivity of linear stiffness to natural frequencies. Mode shape residual vectoris defined as the component-wise differences between unit-length normalized mode shapes of the model and the identified values. Three stiffness parameters,namely theYoung's moduli, are updated,one for each of the three substructures shown in Figure3.Three different models with different modeling assumptions are used in the updating process. The first model is assumed to be a cantilever with no constraints on rotational DOFs resulting in a 14-DOF model. The second model is a semicantilever with constrained rotational DOFs at the first and second mass (12-DOF model) and the third model is a shear building model with no free rotational DOFs at floor levels (7-DOF model).Table 3represents the identified stiffness parameters (Young's moduli) of the three substructures, a comparison between modal parameters of model and the structure, and the values of optimum objective function for the three types of considered models. It can be seen that the cantilever model matches the modal parameters of the structure significantly better than the other considered models. Constraining the rotational DOFs of the structure has considerably deteriorated the model's ability to match the extracted data features and has resulted in inconsistent identified stiffness values. Thus, in the subsequent analysis steps, only the cantilever modeling assumptionis considered for nonlinear model calibration.

\subsection{Step 2: Calibration of Nonlinear Model Parameters}

After identifying the linear model parameters in the first step, the time-invariant parameters of each nonlinear material model are updated by minimizing different response residuals. Assigning wrong or incoherent material behavior to the structuralelementscan be an important source of modeling error. In an attempt to study the effects of this source of error, different types 
of material models are considered in the simplified nonlinear FE models of the structure. The first three models are generated by combining three commonly used hysteretic models for concrete in parallel with a steel material model. The last model is the Bouc-Wen (-Baber-Noori), a more flexible numerical hysteretic model with partially dependent modeling parameters that can make the inverse problem ill-conditioned.For the first three material models five parametersare updated for each substructure versus three parametersfor the last material model (see Table 1). To study the effects of different data features on the accuracy of the nonlinear identification results, sixteen alternative residual measures are used in the formulation ofthe objective function (Table 2) resulting in a total of 4 models $\times 16$ residuals $=64$ optimization setups. Equation 3 defines the residual vectors based different types of data features. Thenatural frequency residuals $\mathbf{r}^{f}$ are defined as the difference between the identified and model calculated time-varying natural frequencies normalized by the identified valuesat considered time instances. Mode shape residuals $\mathbf{r}^{\phi}$ are the differences between unit-length normalized mode shapes of the model and identified values at different time instances. Displacement or acceleration residuals $\mathbf{r}_{d}$ are similarly defined as the difference between measured data and model predicted response time histories at considered times and normalized by the Euclidian norm of measured data.

$\mathbf{r}_{f}=\bigcup_{t=1}^{N_{t}} \bigcup_{n f=1}^{N_{f}}\left(\frac{f_{m}}{f_{i d}}-1\right)_{t}^{n f} ; \mathbf{r}_{\phi}=\frac{1}{N_{\phi}} \bigcup_{t=1}^{N_{t}} \bigcup_{n f=1}^{N_{f}}\left(\frac{\boldsymbol{\Phi}_{m}}{\left\|\boldsymbol{\Phi}_{m}\right\|}-\frac{\boldsymbol{\Phi}_{i d}}{\left\|\mathbf{\Phi}_{i d}\right\|}\right)_{t}^{n f} ; \mathbf{r}_{d}=\bigcup_{n s=1}^{N_{s}} \frac{1}{\left\|d_{i d}^{n s}\right\|} \bigcup_{t=1}^{N_{t}}\left(d_{m}-d_{i d}\right)_{t}^{n s}$

In this equation, $\bigcup_{i=1}^{n} \ldots$ denotes the merging/stacking of $n$ column vectors into a larger column vector. Subscripts $m$ and $i d$ refer to the model and identified features, respectively, $t$ is the time instance index, superscripts $n f$ and $n s$ are the vibration mode and story numbers, respectively, $f$ is the natural frequency, $\boldsymbol{\Phi}$ is the mode shape, $d$ is the displacement or accelerationresponse, $N_{t}$ and $N_{\phi}$ are the numbers of considered time-instances and numbers of mode shape components, and $N s$ is the total number of stories.. The simulated annealing (SA)global optimization method is used to minimize the different objective functions. Table 4 reports the initial values of updating parameters in the optimization process. However, the implemented global optimization is not too sensitive to the initial values of parameters.It is worth noting that each case of global optimization would approximately take 48 hours of CPU time using an average PC ( $2 \mathrm{GHz}$ processor and 8 GB RAM). In this study, the optimization runs have been carried out using the Tufts cluster. The cluster includes approximately $170+$ compute nodes and a peak performance of roughly $60+$ Teraflops. Each cluster node has 12, 16, or 20 cores using three different Intel CPUs and the node memory can vary between 24 to 256 gigabytes. The implemented software for this application, namely OpenSees and Matlab have been made available in the Cluster environment.

Tables 5 and 6report the statistics (mean and standard deviation) of the identified parameters for models 1 to 3 and model 4, respectively, using different residualsexcept r10 and r11. Residuals r10 and r11 are not included in these statistics since these two residuals correspond to the largest updating error as reported next in Figure 6.Parameters of the nonlinear models, especially for the first three physics-based models, can provide information about the amount and type of nonlinearity in different substructures. Bouc-Wen model parameters can also provide someinformation about the nonlinear behavior of the structure, but the dependency and lack of physical definition of the parameters make their interpretation more difficult. From Table 5 it can 
be observed that the identified parameters have relatively large variations using different residuals. This may underline the sensitivity of the identification results to the data features used in the updating process or high uncertainty in the identified parameters. The estimated parameter $\alpha$ is consistently found to be larger for the first substructure across different models. A larger value of $\alpha$ defines a larger contribution of concrete to the overall parallel stiffness, which can be an indication of larger nonlinear behavior at the bottom of the shear wall (substructure 1). The identified parameters also show large variability across different models, whichis due to the different formulations of the three constitutive models. It should also be noted that even though the nonlinear material parameters show significant variability across residuals and material models, most of the calibrated models can fit accurately the measured acceleration, displacement and modal parameters of the first two modes.In the Bouc-Wen model, it can be observed that similar to the first three material models, the most nonlinear substructure is identified at the lowest story. Note that in this model, smaller aindicates more nonlinear behavior, but larger values are obtained for $\gamma$ and $\beta$ for higher stories, which also indicate more nonlinear behavior. The multiplication of the parameters of the Bouc-Wen modelhas resulted in greater dependency of the parameters of the model to each other and strong compensation effect as it has been reported in $[33,34,45]$.

In order to quantify the performance of different calibrated models, different error metrics are defined based on the difference between the model predicted and the measured/simulated data quantities as shown in Equation 4.

$e_{i}=\frac{\left\|y_{i}^{m}-y_{i}^{i d}\right\|}{\left\|y_{i}^{i d}\right\|}$

Equation 4 is used to define 24 different error metrics. The error metrics used in this studyare based on the following response features: (1-7) acceleration time histories of each floor between 0 to 50 seconds, (8-14) displacement time histories of each floor 0-50s, (15-21) dissipated hysteretic energy at each story $0-50 \mathrm{~s}$, and (22-24) natural frequency at 25 selected times for the first three translational modes.

Figure 6 shows the mean and range of time-domain error metrics (acceleration, displacement and dissipated energy time histories) over the seven stories for different residuals and material models used. In the right column, the frequency domain error metrics are also shown for the three modes and four material models. The vertical axes correspond to the residual number listed in Table 1. For the time-domain errors, the horizontal lines in the plot represent the error range in the seven stories and the dots refer to the mean values. The black vertical lines indicate the smallest error containing the three lowest mean residual errors, i.e., three residuals will have smaller or equal mean error values. Table 7 shows the average over all 24 error metrics for each residual and each material model. FromFigure 6 and Table 7, it can be seen that (1) in general residuals based on acceleration and displacement time histories provide the best overall fit for different error metrics, (2) the inclusion of more data points (e.g., r2 to r3, and r4 to r5) in the residual vectoralways improves the response predictions, especially for the case of the acceleration residualwhich is characterized by more erratic changes and richer frequency content, (3) the fourth considered material model is not able to fit the measured data using any of the considered residuals, (4) the natural frequency error for the third mode is consistently larger than that the first two modes indicating the inability of considered models to fit this mode, (5) the 
shape of mean acceleration error and mean displacement error plots in Figure 6 are similar while they are different from themean energy error plot, (6) residuals $\mathrm{r} 10$ and r11, which are solely based on hysteretic energy, provide large errors in other three metrics, however, residual r16, which includes a combination of energy and frequency features provide reasonably good fits between the model and data, (7) using residuals $\mathrm{r} 8$ and $\mathrm{r} 9$, which can be interpreted as increments in the hysteretic energy (r10 and r11), can improve the updating results in comparison to the use of r10 and r11.As an illustration, Figure 7 shows a comparison between model predicted and measured data features for a calibrated model based on the third material model (Yassin-Pinto) and $\mathrm{r} 12$ residual (combination of modal parameters and acceleration). It can be observed that the updated model can closely match the natural frequencies of the first two translational modes as well as the acceleration and displacement time histories. The hysteretic energy plots of the model and the data have larger discrepancies thatcould be due to accumulation of small errors in shear and displacement predictions over time. It is worth noting that the time-domain error metrics are summation of response discrepancies at 12,000 points so even for relatively large error metrics,the response features can match well as shown in Figure 7.

\subsection{Model Validation}

In this section, the performance of the simplified calibrated models is evaluated for predicting the response of structure to two earthquake excitations that are different from the one used in the calibration, or updating process. The "measured/exact" response of the structure is simulated using the detailed FE model of the structure discussed in Section 2.1. The considered ground motion records for model validation arethe transverse component of the San Fernando 1971 earthquake recorded at Van Nuys station and the $360^{\circ}$ component of the Northridge 1994 earthquake recorded at Sylmar station. Both these records were used in the shake table test of the shear wall specimen and the detailed FE model was tuned manually to represent the measured data reasonably well.

Figure 8 plots the acceleration time histories of these two ground motion records reproduced on the shake table (i.e., actual measured signals on the shake table). The peak ground acceleration of the first record issmaller while that of the second record is larger than the peak ground acceleration of the record used for model calibration. Figure 9 compares the predicted responseusing three calibrated models based on materials 1-3 and residual $r 7$ with their corresponding exact response features.From the previous section, it was observed that the choice of residual $\mathrm{r} 7$ provided reasonably accurate error metrics, especially for acceleration and displacement response predictions. These response features are usually most informative about the performance of structures for future loading. Therefore, the calibrated models using residual r7 are used for validation purposes. The left column compares the predicted response features for the San Fernando earthquakewhile the right column represent predicted response features for the Northridge earthquake. The five horizontal subplots from top to bottom present the roof acceleration, roof displacement, instantaneous natural frequencies of the first two modes, and the dissipated hysteretic energy of the first story, respectively. The acceleration and displacement plots are zoomed in the most nonlinear part of response, which usually have the largest estimation errors. It can be observed that the predicted displacements and accelerations for all three models and two earthquakes are in excellent agreement with the exact response. The computed instantaneous natural frequencies are averagedover 0.5 second windows by passing the data through a moving average filter of the order of 120 (half of the sampling frequency).Even though the considered residual $r 7$ does not include modal parameters, the natural frequencies of 
the first two modes are in relatively good agreement with their exact counterparts for both earthquakes. However, the match is slightly better for the weaker ground motion. For the stronger earthquake, the calibrated model with Kent-Scott-Park material (Model 2) performs better than the other two models. The first story hysteretic energy values are estimated by multiplication of shear force (product of total acceleration with thecorresponding nodal mass) and displacement. The plots are smoothed by a moving average filter of order 100. Results shown in Figure 9 indicate that none of the three models can predict the hysteretic energy time histories accurately. As previously mentioned, this can be due to accumulation of prediction errors over a large number of time instances.

\section{Identificationusing the Unscented Kalman Filter}

In this section, two different simplified models of the structure are formulated in state-space and the Unscented Kalman filter (UKF) is used for nonlinear identification. The state-space models correspond to a 7-DOF shear building model and a 14-DOF cantilever beam-column. Similar to the FE models, the elements of the state-space models are divided into three substructures: first story, second story, and upper stories. The nonlinearity is assumed to be concentrated at the first two stories and the upper stories are modeled as linear components. Bouc-Wen hysteretic material model is considered for the first and second story stories. The Bouc-Wen model proved to be inaccurate and unstable for FE model calibration in the previous section, whichmostly pertained to an offline updating process. Nonetheless, when combined withthe filtering approach,instability may be prevented due to the onlinecorrectionfrom measurement residuals. In addition, this material model has aconvenient analytical form suitable for application byadaptive methods for nonlinear state-space modelscalibration/identification. The assigned lumped masses at the nodes are the same as those used in the FE models and the elastic stiffness values of the substructures are updated to match the identified modal parameters at the initial low amplitude parts of the excitation before running the filter for calibrating the nonlinear models. Table 8 compares the identified modal parameters and those of the state-space models after initial stiffnesscalibration. It can be seen that the cantilever model provides a significantly improved matchto the measured response.

The simulated nonlinear response of the structures for the Woodland Hills earthquake is considered as the reference measurement. The UKF is used for nonlinear identification based on three cases of available measurements: (1) acceleration response at all floors, (2) accelerationat all floors and displacement at the $2^{\text {nd }}$ floor, and (3) acceleration at all floors and displacements at $2^{\text {nd }}$ and $7^{\text {th }}$ floors. The parameters of Bouc-Wen model are updated at each time step based on the measurement corrections. Figures 10 and 11 represent the predicted acceleration and displacement responses at floors $1,3,5$, and 7 by the UKF for the cantilever beam and shear building models, respectively. From this figure, it can be seen that, the cantilever model can accurately match the acceleration data. It is worth noting that in a parameter identification problem, the ideal identification results will be obtained when the employed model is truly capable of reproducing structural response. However, this is not the case for the implemented model herein, since a reduced order approximation is sought. For this reason, the filter needs to have acceleration measurements from all the structural DOFs for a better performance. It is obvious that partial displacement measurements are also beneficial.Fusion of displacement time histories into the observations is known to facilitate parameter convergence in cases of significant presence of noise or, in this case, modeling errors [29]. In this case as well, for the cantilever model the displacements at all floors are estimated accurately when only limited 
displacement data is used in the identification. From Figure 10, it can be observed that the displacements estimates are nearly equal to the simulated response of the structure in all stories especially for the third case. Accurate estimates of the floor displacements in structures can be used for damage detection [48], which often cannot be estimated accurately from the acceleration data due to numerical errors in the integration process and noisy measurements. From Figure 11, it can be observed that the calibrated shear model provide significantly larger response prediction errors compared to the cantilever model. Addition of displacement data will slightly improve the displacement prediction of the model in some floors but drastically degrades the acceleration predictions. This observation highlights the inability of this model to match all the states of the structure consistently and existence of large modeling errors. The discussion abovealso highlights the importance of underlying modeling assumptions in the process of identification.

\section{Conclusions}

Simplified nonlinear FE models and state-space models of a seven-story shearwall structure are identified using the simulated response of the structure to a historic earthquake ground motion delivered via a detailed and calibrated FE model. The parameters of the detailed FE model - based on the information from the geometry and material properties of the structure were calibrated such that the response of the model matches the recorded response from the structure during certain seismic base excitation tests on a shake table [49]. The role of two important factors on the performance of the identified/calibrated models is studied, which are: (1) modeling errors, and (2) data featuresused in identification. Effects of modeling errors are studied by considering two modeling assumptions (cantilever and shear building model) and four types of material hysteretic models. It is observed that the shearbuilding modelfor the considered structure will provide significantly larger identification errors than the cantilever model. In the FE model updating process, it was also observed that the three physics-based hysteretic material models (Popovics-Pinto, Kent-Pinto, and Yassin-Pinto) provided good match to the simulated response while the phenomenological Bouc-Wen model provided large prediction errors. The identified models are validated by predicting the structural response for two earthquakes that are different from the record used in the model calibration. Among the first three models, the KentPinto model provided the best response prediction during the validation process. Sixteen alternative residualsbased on four types of measured response features (modal parameters, displacements, accelerations, and hysteretic energy) and their combinations are employed and cross-assessed for model calibration. It is found that, in general, use of acceleration and displacement responses, or their combination with modal data provides the best overall match between the calibrated models and simulated data. On the other hand, use of energy data alone results in large estimation errors for the calibrated models. The Unscented Kalman filter is also used for nonlinear identification of the structure modeled in the state-space form. Two statespace models with cantilever and shearbuilding assumptions are formulated. The parameters of Bouc-Wen materials for each model are updated at each time step based on different types of measurements (acceleration and displacement).It is observed that the calibrated cantilever model provides consistently more accurate response predictions than the shear model, which is in agreement with the observed results in the model updating process. Addition of displacement data in the identification process improves the displacement prediction of the cantilever model while it worsens the acceleration prediction of the shear model. Therefore, in presence of large modeling errors (e.g., shear model assumption here) fusion of data in the identification process cannot improve the results. To the contrary, when the choice of forward model is appropriate 
inclusion of heterogeneous information, i.e., both displacement and acceleration records, proves beneficial.

\section{ACKNOWLEDGMENTS}

Partial support of this project by the National Science Foundation Grant No. 1254338, which was awarded under the Faculty Early Career Development (CAREER) program, is acknowledged. The authors would like to acknowledge Mr. Durwood Marshall from Tufts Technology Services for his assistance in use of the Tufts cluster. The opinions, findings, and conclusions expressed in the paper are those of the authors and do not necessarily reflect the views of the individuals and organizations involved in this project. 


\section{REFERENCES}

[1] S.W. Doebling, C.R. Farrar, M.B. Prime, D.W. Shevitz, Damage identification in structures and mechanical systems based on changes in their vibration characteristics: a detailed literature survey, Los Alamos national laboratory, Los Alamos, NM, USA, LA-13070-MS, report, 1996.

[2] H. Sohn, C.R. Farrar, F.M. Hemez, D.D. Shunk, D.W. Stinemates, B.R. Nadler, A review of structural health monitoring literature: 1996-2001, Los Alamos national laboratory, Los Alamos, NM, USA, LA-13976-MS, technical report, 2003.

[3] E.P. Carden, P. Fanning, Vibration based condition monitoring: a review, Struct. Health Monit., 3(4) (2004) 355-377.

[4] G. Kerschen, K. Worden, A.F. Vakakis, J.C. Golinval, Past, present and future of nonlinear system identification in structural dynamics, Mech. Syst. Sig. Process., 20 (2006) 505-592.

[5] J.E. Mottershead, M.I. Friswell, Model updating in structural dynamics: a survey, J. Sound Vib., 167(2) (1993) 347-375.

[6] A. Teughels, G. De Roeck, Damage detection and parameter identification by finite element model updating, Arch. Comput. Method. E., 12(2) (2005) 123-164.

[7] B. Moaveni, X. He, J.P. Conte, R.A. De Callafon, Damage identification of a composite beam using finite element model updating, Comput.-Aided Civ. Inf., 23(5) (2008) 339-359.

[8] B. Moaveni, X. He, J.P. Conte, J.I. Restrepo, Damage identification study of a seven-story full-scale building slice tested on the UCSD-NEES shake table, Struct. Saf., 32(5) (2010) 347-356.

[9] B. Moaveni, A. Stavridis, G. Lombaert, J. Conte, P. Shing, Finite element model updating for assessment of progressive damage in a three-story infilled RC frame, J. Struct. Eng., 139 (2013) 1665-1674.

[10] I. Behmanesh, B. Moaveni, Probabilistic identification of simulated damage on the Dowling Hall Footbridge through Bayesian FE model updating, Struct. Control. Health Monit., in press.

[11] B. Moaveni, I. Behmanesh, Effects of changing ambient temperature on finite element model updating of the Dowling Hall Footbridge, Eng. Struct., 43 (2012) 58-68.

[12] C. Papadimitriou, D.C. Papadioti, Component Mode Synthesis Techniques for Finite Element Model Updating, Computers and Structures, 126(2013)15-28.

[13] F.M. Hemez, S.W. Doebling, Review and assessment of model updating for non-linear, transient dynamics, Mech. Syst. Sig. Process., 15(1) (2001) 45-74.

[14] P.J. Beardsley, F.M. Hemez, S.W. Doebling, Updating nonlinear finite element models in the time domain, In: Proceedings of 2nd international workshop on structural health monitoring, Stanford, CA, 1999.

[15] M. Spiridonakos, E. Chatzi, Metamodeling of structural systems with parametric uncertainty subject to stochastic excitation, Safety, Reliability, Risk and Life-Cycle Performance of Structures and Infrastructures - Proc. of the 11th International Conference on Structural Safety and Reliability(ICOSSAR 2013), Columbia University, New York, NY, 2013.

[16] W. Song, M. So, S.J. Dyke, T.G. Harmon, G.J. Yun, Nonlinear RC structure model updating using ambient vibration data, ACI Special Publication, ACI Convention, 2008.

[17] S.K. Kunnath, J.B. Mander, L. Fang, Parameter identification for degrading and pinched hysteretic structural concrete systems, Eng. Struct., 19(3) (1997) 224-232.

[18] E. Asgarieh, B. Moaveni, A. Stavridis, Nonlinear structural identification of a three-story infilled frame using instantaneous modal parameters, Proc. of 30th International Modal Analysis Conference (IMAC-XXX), Jacksonville, Florida, USA, 2012.

[19] E.Asgarieh, B. Moaveni, A. Stavridis, Nonlinear finite element model updating of a large-scale infilled frame structure based on instantaneous modal parameters, Proc. of 31stInternational Modal Analysis Conference (IMAC-XXXI), Garden Grove, California, USA, 2013. 
[20] W. Song, S.J. Dyke, S.J., T. Harmon, Application of nonlinear model updating for a reinforced concrete shear wall, J. Eng. Mech., ASCE, 139(5) (2013) 635-649.

[21] S. Kirkpatric, C.D. Gelatt, M.P. Vecchi, Optimization by simulated annealing, Science 220 (4598) (1983) 671-680.

[22] N. Distefano, A. Rath, System identification in nonlinear structural seismic dynamics, Comput. Method. Appl. Mech. Eng., 5(3) (1975) 353-372.

[23] N. Distefano, A. Rath, Sequential identification of hysteretic and viscous models in structural seismic dynamics, Comput. Method. Appl. Mech. Eng., 6 (1974) 219-232.

[24] M. Hoshiya, E. Saito, Structural identification by extended Kalman filter, J. Eng. Mech., 110(12) (1984) 1757-70.

[25] J.S. Lin, Y. Zhang, Nonlinear structural identification using extended Kalman filter, Comput. Struct., 52(4) (1994) 757-764.

[26] M. Wu, A.W. Smyth, Application of unscented Kalman filter for real-time nonlinear structural system identification, Struct. Control. Health Monit., 14(7) (2007) 971-990.

[27] S. Mariani, A. Ghisi, Unscented Kalman filtering for nonlinear structural dynamics, Nonlinear Dynam., 49 (2007) 131-150.

[28] S. Eftekhar Azam, M. Bagherinia, S. Mariani, Stochastic system identification via particle and sigma-point Kalman filtering, Scientia Iranica, 19(4) (2012) 982-991.

[29] E. Chatzi, A. Smyth, The unscented Kalman filter and particle filter methods for nonlinear structural system identification with non-collocated heterogeneous sensing, Struct. Control. Health Monit., 16 (2009) 99-123.

[30] W. Song, S.J. Dyke, Real-time dynamic model updating of a hysteretic structural system, J. Struc. Eng., ASCE, 140(3), (2014) 04013082.

[31] Y.K. Wen, Method for random vibration of hysteretic systems, J. Eng. Mech., ASCE, 102 (2) (1976) 249263.

[32] T.T. Baber, M. Noori, Random vibration of degrading, pinching systems, J. Eng. Mech., ASCE, 111(8) (1985) 1010-26.

[33] M. Ismail, F. Ikhouane, J. Rodellar, The hysteresis Bouc-Wen model, a survey, Archives of Computational Methods in Engineering, 16 (2009) 161-188.

[34] F. Ikhouane, J.E. Hurtado, J. Rodellar, Variation of the hysteresis loop with the Bouc-Wen model parameters, Nonlinear Dynamics, 48(4) (2007) 361-380.

[35] K. Erazo, E. M. Hernandez, A model-based observer for state and stress estimation in structural and mechanical systems: Experimental validation, Mech. Syst. Sig. Process., 43(1-2) (2014) 141-152.

[36] E. A. Wan, R. Van der Merwe, The unscented Kalman filter for nonlinear estimation, Mech. Syst. Sig. Process., Commun. Contr., 2000.

[37] S. J. Julier. The Scaled Unscented Transformation, Proc. Amer. Control Conf., 2002.

[38] M. Panagiotou, J. Restrepo, J. Conte, Shake-table test of a full-scale 7-story building slice, Phase I: rectangular wall, J. of Struct. Eng., 137(6) (2011) 691-704.

[39] S. Mazzoni, M.H. Scott, F. McKenna, G.L. Fenves, et al., Open System for Earthquake Engineering Simulation - user manual (version 1.7.3), Pacific Earthquake Engineering Research Center, University of California, Berkeley, California, 2006.

[40] F. Filippou, E. Popov, V. Bertero, Modeling of reinforced concrete joints under cyclic excitations, J. Struct. Eng. 109(11) (1983).

[41] S. Popovics, A numerical approach to the complete stress strain curve for concrete, Cement and concrete research, 3(5) (1973) 583-599. 
[42] D.C. Kent, R. Park, Flexural members with confined concrete, J. Struct. Div.-ASCE, 97(ST7) (1971) 19691990.

[43] M.H.M. Yassin, Nonlinear analysis of prestressed concrete structures under monotonic and cycling loads, $\mathrm{PhD}$ dissertation, University of California, Berkeley; 1994.

[44] I.D. Karsan, J.O. Jirsa, Behavior of concrete under compressive loadings, J. Struc. Div., ASCE, 95(12), (1969) 2543-2563.

[45] E. Asgarieh, B. Moaveni, Nonlinear finite element model updating of an infilled frame based on identified time-varying modal parameters during an earthquake, J. Sound. Vib., 333 (23) (2014) 6057-6073.

[46] P. Van Overschee, B. De Moore, Subspace identification for linear systems, Norwell, MA, USA, Kluwer Academic Publishers, 1996.

[47] B. Moaveni, E. Asgarieh, Deterministic-stochastic subspace identification method for identification of nonlinear structures as time-varying linear systems, Mech. Syst. Sig. Process., 31 (2012) 40-55.

[48] K. Erazo, E. M. Hernandez, State Estimation in Nonlinear structural Systems, Proc. of 32th International Modal Analysis Conference (IMAC-XXXII), Jacksonville, Florida, USA, 2014.

[49] B. Moaveni, A. R. Barbosa, J. P. Conte, F. M. Hemez, Uncertainty analysis of system identification results obtained for a seven-story building slice tested on the UCSD-NEES shake table,Struct. Health Monit., 21 (2014) 466-483. 


\section{TABLES}

Table 1.Updated parameters in each material model

\begin{tabular}{ccc}
\hline Hysteretic model & $\begin{array}{c}\text { Parameters } \\
\text { in each Substruc. }\end{array}$ & $\begin{array}{c}\text { No. of updating } \\
\text { parameters }\end{array}$ \\
\hline Model 1: Popovics-Pinto & $\alpha, \sigma_{\mathrm{c}},\left(\varepsilon_{\mathrm{c}}=\varepsilon_{\mathrm{cu}}\right), \mathrm{F}_{\mathrm{y}}, \mathrm{b}$ & $3 \times 5=15$ \\
\hline Model 2: Kent-Pinto & $\alpha, \sigma_{\mathrm{c}}, \varepsilon_{\mathrm{cu}}, \mathrm{F}_{\mathrm{y}}, \mathrm{b}$ & $3 \times 5=15$ \\
\hline Model 3: Yassin-Pinto & $\alpha, \sigma_{\mathrm{c}}, \varepsilon_{\mathrm{cu}}, \mathrm{F}_{\mathrm{y}}, \mathrm{b}$ & $3 \times 5=15$ \\
\hline Model 4: Bouc-Wen & $\alpha,(\beta=\gamma), \delta_{\eta}$ & $3 \times 3=9$ \\
\hline
\end{tabular}

Table 2. Considered residuals in the objective function and data features used in each residual vector

\begin{tabular}{c|cc}
\hline Residual \# & Data Feature & Residual Vector Size \\
\hline r1 & Time-varying modal parameters of 3 modes & 600 \\
\hline r2 & Accelerations (at 25 selected points) & 175 \\
\hline r3 & Accelerations (all point 0-50 s) & 84,000 \\
\hline r4 & Displacements (at 25 points) & 175 \\
\hline r5 & Displacements (all points 0-50 sec) & 84,000 \\
\hline r6 & r2 and r4 & 350 \\
\hline r7 & r3 and r5 & 168,000 \\
\hline r8 & Acceleration $\times$ displacement (at 25 points) & 175 \\
\hline r9 & Acceleration $\times$ displacement (all point 0-50 s) & 84,000 \\
\hline r10 & Hysteretic energy (at 25 points) & 175 \\
\hline r11 & Hysteretic energy (all point 0-50 s) & 84,000 \\
\hline r12 & r1 and r2 & 775 \\
\hline r13 & r1 and r4 & 775 \\
\hline r14 & r1, r2 and r4 & 950 \\
\hline r15 & r1 and r8 & 775 \\
\hline r16 & r1 and r10 & 775 \\
\hline
\end{tabular}


Table 3. Linear model calibration results

\begin{tabular}{|c|c|c|c|c|c|c|c|c|c|c|}
\hline \multirow{2}{*}{ Model } & \multicolumn{3}{|c|}{$\begin{array}{c}\text { Updated stiffness } \\
{\left[10^{6} \mathrm{MPa}\right]}\end{array}$} & \multicolumn{3}{|c|}{ Natural frequencies [Hz] } & \multicolumn{3}{|c|}{ MAC ${ }^{*}$} & \multirow{2}{*}{ 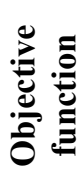 } \\
\hline & Sub 1 & Sub 2 & Sub 3 & $\begin{array}{l}\text { Mode } 1 \\
f_{1}=1.88\end{array}$ & $\begin{array}{l}\text { Mode } 2 \\
f_{2}=9.34\end{array}$ & $\begin{array}{l}\text { Mode } 3 \\
f_{3}=23.08\end{array}$ & Mode 1 & Mode 2 & Mode 3 & \\
\hline 1- Cantilever & 67.43 & 62.81 & 2.79 & 1.84 & 9.36 & 24.45 & 0.99 & 0.99 & 0.99 & 0.034 \\
\hline 2- Semi-Cantilever & 54.33 & 3.93 & 19.24 & 1.76 & 10.08 & 22.09 & 0.96 & 0.87 & 0.86 & 0.051 \\
\hline 3- Shear Building & 5.17 & 67.22 & 0.28 & 2.15 & 6.26 & 9.82 & 0.98 & 0.91 & 0.71 & 1.07 \\
\hline
\end{tabular}

${ }^{*}$ MAC stands for modal assurance criteria

Table 4.Initial values of updating parameters $\left(\alpha, \sigma_{\mathrm{c}}, \varepsilon_{\mathrm{cu}}, \mathrm{F}_{\mathrm{y}}, \mathrm{b}\right.$ for Models 1-3 and $\alpha, \beta, \delta_{\eta}$ for Model 4) used in the optimization process

\begin{tabular}{lcl}
\hline & \multicolumn{1}{c}{ Models l-3 } & Model 4 \\
\hline Substruc. 1 & $0.46,0.96,33,64,0.64$ & $2,1,0.5$ \\
\hline Substruc. 2 & $94,0.03,75,32,0.94$ & $2,1,0.5$ \\
\hline Substruc. 3 & $8.5,0.42,55,95,0.39$ & $2,1,0.5$ \\
\hline
\end{tabular}

Table 5. Statistics (mean/standard deviation) of identified parameters for material models 1-3 using 14 different residuals (all except r10 and r11)

\begin{tabular}{c|c|c|c|c|c|c|c|c|c}
\hline & \multicolumn{2}{|c|}{ Model 1 (Popovics-Pinto) } & \multicolumn{2}{c|}{ Model 2 (Kent-Pinto) } & \multicolumn{3}{c}{ Model 3 (Yassin-Pinto) } \\
\hline & Sub 1 & Sub 2 & Sub 3 & Sub 1 & Sub 2 & Sub 3 & Sub 1 & Sub 2 & Sub 3 \\
\hline $\boldsymbol{\alpha}$ & $0.54 / 0.30$ & $0.15 / 0.15$ & $0.12 / 0.09$ & $0.70 / 0.20$ & $0.29 / 0.22$ & $0.16 / 0.11$ & $0.61 / 0.19$ & $0.30 / 0.22$ & $0.17 / 0.10$ \\
\hline $\boldsymbol{\sigma}_{\mathbf{c}}{ }^{*}$ & $-2027 / 1420$ & $-2241 / 1751$ & $-1469 / 1096$ & $-1544 / 1345$ & $-2144 / 1441$ & $-1027 / 600$ & $-2103 / 1296$ & $-2365 / 1372$ & $-1786 / 1089$ \\
\hline $\boldsymbol{\varepsilon}_{\mathbf{c}}$ & $-2.83 / 2.19$ & $-0.61 / 1.01$ & $-0.80 / 1.23$ & $-0.04 / 0.04$ & $-0.24 / 0.29$ & $-0.48 / 0.53$ & $-0.06 / 0.04$ & $-0.66 / 1.58$ & $-0.79 / 0.92$ \\
\hline $\mathbf{F}_{\mathbf{y}}{ }^{*}$ & $793 / 503$ & $1765 / 958$ & $1241 / 565$ & $1165 / 731$ & $1476 / 800$ & $1165 / 586$ & $924 / 710$ & $1296 / 758$ & $855 / 627$ \\
\hline $\mathbf{B}$ & $0.24 / 0.12$ & $0.63 / 0.30$ & $0.46 / 0.28$ & $0.38 / 0.26$ & $0.53 / 0.29$ & $0.52 / 0.27$ & $0.37 / 0.29$ & $0.40 / 0.24$ & $0.57 / 0.25$ \\
\hline
\end{tabular}

*units are in $\mathrm{MPa}$

Table 6. Statistics (mean/standard deviation) of Bouc-Wen model parameters using 14 different residuals (all except r10 and r11)

\begin{tabular}{c|c|c|c}
\hline & Sub 1 & Sub 2 & Sub 3 \\
\hline $\boldsymbol{\alpha}$ & $0.13 / 0.05$ & $0.63 / 0.25$ & $0.72 / 0.29$ \\
\hline $\boldsymbol{\beta}=\boldsymbol{\gamma}$ & $758 / 591$ & $900 / 587$ & $1651 / 369$ \\
\hline $\boldsymbol{\delta}_{\eta}$ & $321 / 112$ & $290 / 160$ & $291 / 153$ \\
\hline
\end{tabular}


Table 7.Average error metrics for updated model using different residuals and material

\begin{tabular}{c|c|c|c|c}
\hline Residual & Model 1 & Model 2 & Model 3 & Model 4 \\
\hline r1 & 0.61 & 0.47 & 0.56 & 4.10 \\
\hline r2 & 0.48 & 0.56 & 0.48 & 7.23 \\
\hline r3 & 0.37 & 0.45 & 0.41 & 5.33 \\
\hline r4 & 0.48 & 0.32 & 0.42 & 3.66 \\
\hline $\mathbf{r 5}$ & 0.34 & 0.32 & 0.38 & 1.64 \\
\hline $\mathbf{r 6}$ & 0.45 & 0.65 & 0.45 & 1.36 \\
\hline $\mathbf{r 7}$ & 0.39 & 0.47 & 0.39 & 1.36 \\
\hline $\mathbf{r 8}$ & 0.49 & 0.54 & 0.41 & 4.16 \\
\hline $\mathbf{r 9}$ & 0.43 & 0.56 & 0.45 & 8.18 \\
\hline $\mathbf{r 1 0}$ & 0.57 & 0.47 & 0.54 & 8.32 \\
\hline $\mathbf{r 1 1}$ & 0.78 & 0.50 & 0.53 & 68.08 \\
\hline $\mathbf{r 1 2}$ & 0.44 & 0.76 & 0.44 & 0.91 \\
\hline $\mathbf{r 1 3}$ & 0.44 & 0.39 & 0.43 & 4.16 \\
\hline $\mathbf{r 1 4}$ & 0.34 & 0.46 & 0.52 & 1.73 \\
\hline $\mathbf{r 1 5}$ & 0.40 & 0.49 & 0.57 & 4.16 \\
\hline $\mathbf{r 1 6}$ & 0.43 & 0.49 & 0.45 & 6.59 \\
\hline
\end{tabular}

Table 8.Natural frequencies / MAC of calibrated linear state-space models compared with identified data

\begin{tabular}{c|c|c|c}
\hline & Mode 1 & Mode 2 & Mode 3 \\
\hline Identified & $1.88 /-$ & $9.34 /-$ & $23.09 /-$ \\
Cantilever & $1.82 / 1.00$ & $9.36 / 0.99$ & $23.09 / 0.99$ \\
Shear-Building & $1.48 / 0.67$ & $11.16 / 0.33$ & $22.38 / 0.32$ \\
\hline
\end{tabular}




\section{FIGURES}

(a)

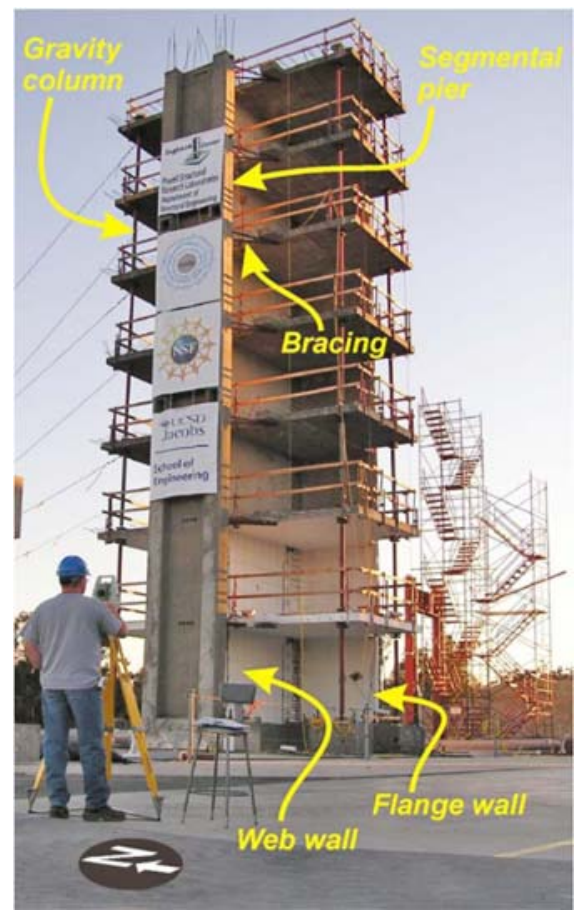

(d)

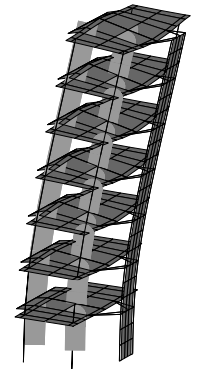

$\mathbf{f}_{1}=1.88 \mathrm{~Hz}$

Mode 1 translational

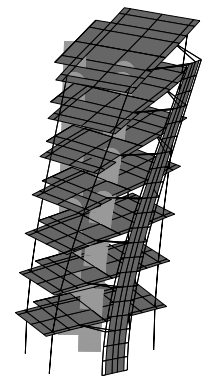

$\mathbf{f}_{2}=1.98 \mathrm{~Hz}$
Mode 1 torsional

(b)

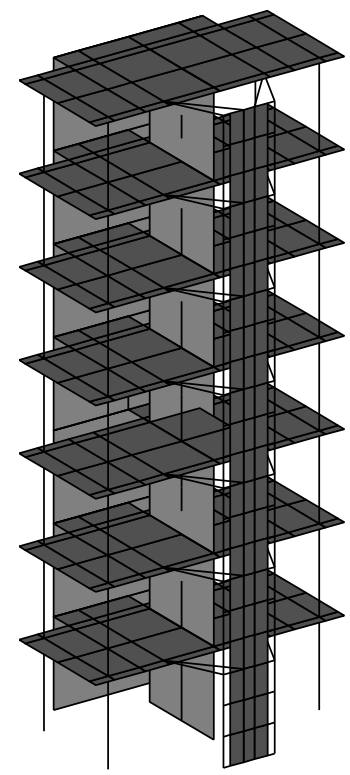

(c)

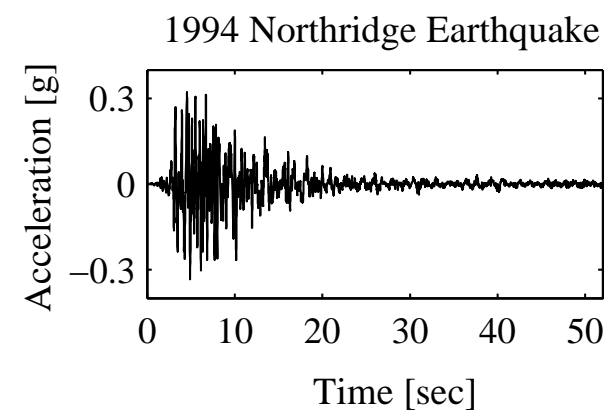

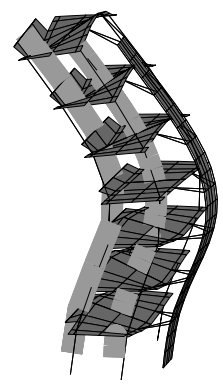

$\mathbf{f}_{4}=9.34 \mathrm{~Hz}$

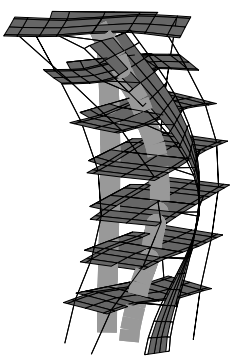

$\mathbf{f}_{5}=9.50 \mathrm{~Hz}$

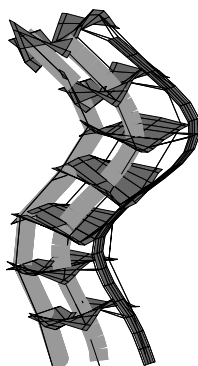

$\mathbf{f}_{17}=23.08 \mathrm{~Hz}$

Mode 2 translational

Mode 2 torsional

Mode 3 translational

Fig. 1 (a) Seven-story test structure, (b) detailed model used for response simulation, (c) earthquake record used as input excitation, and (d) the first three translational and the first two torsional modes of the model. 

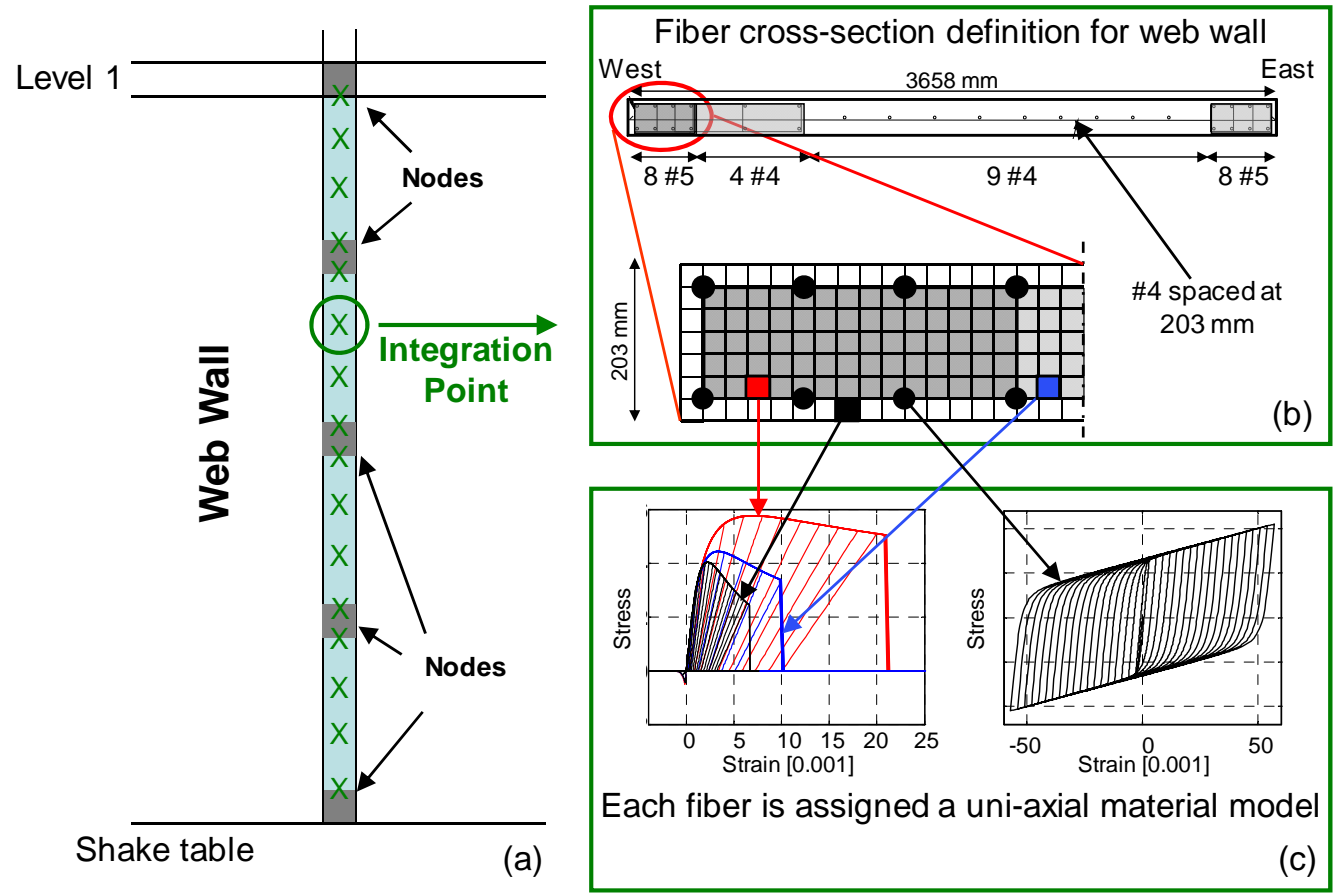

Fig. 2 (a) Elevation view of the first story of web wall in the detailed model, (b) cross-section of the web wall with different levels of confinement of concrete (no confinement: white, moderate confinement: light grey, and high confinement: dark grey background), and (c) uniaxial constitutive laws for unconfined and confined concrete and steel reinforcement. 

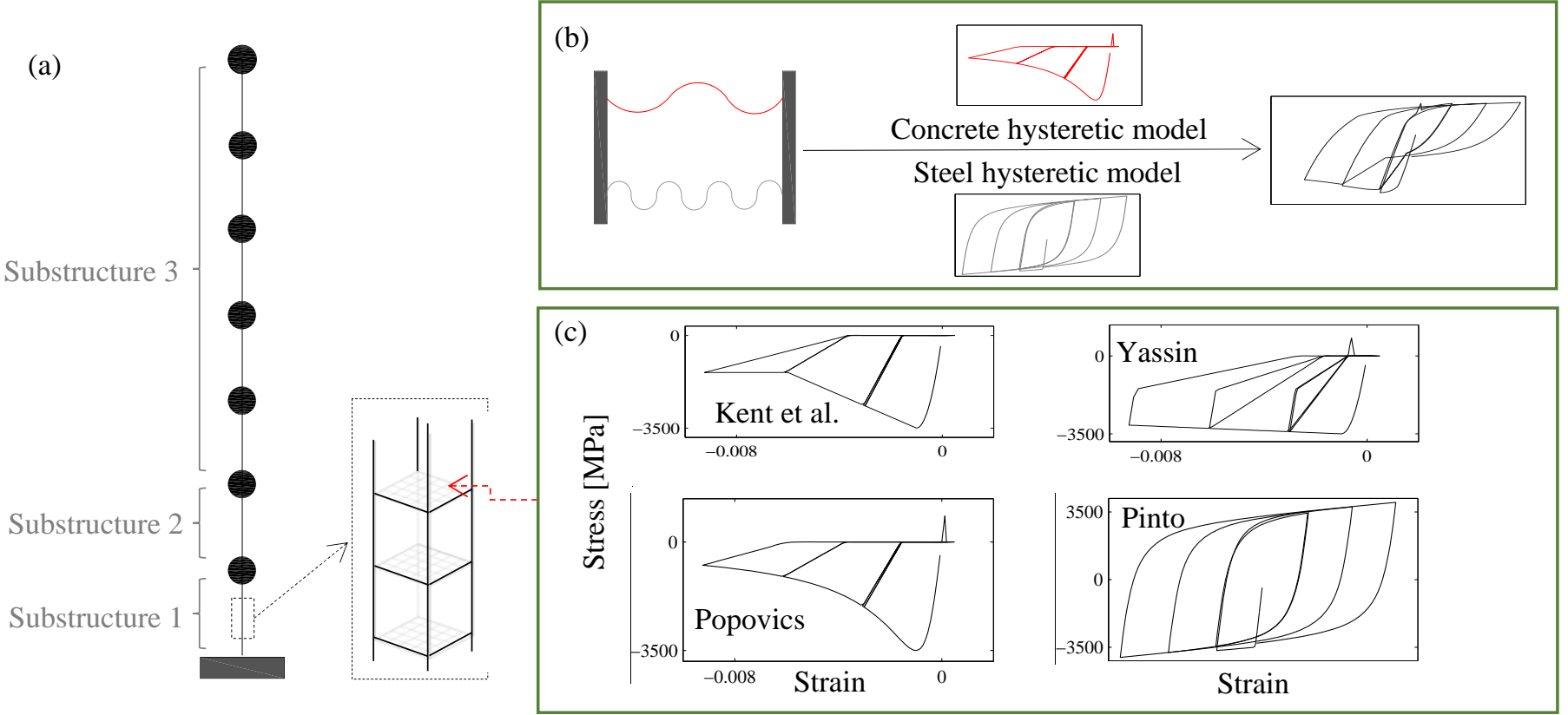

Fig. 3 (a) Simple model with nonlinear beam-column fiber elements, (b) generated parallel material model by combining selected hysteretic models for steel and concrete, (c) considered hysteretic models for generating the parallel material model 

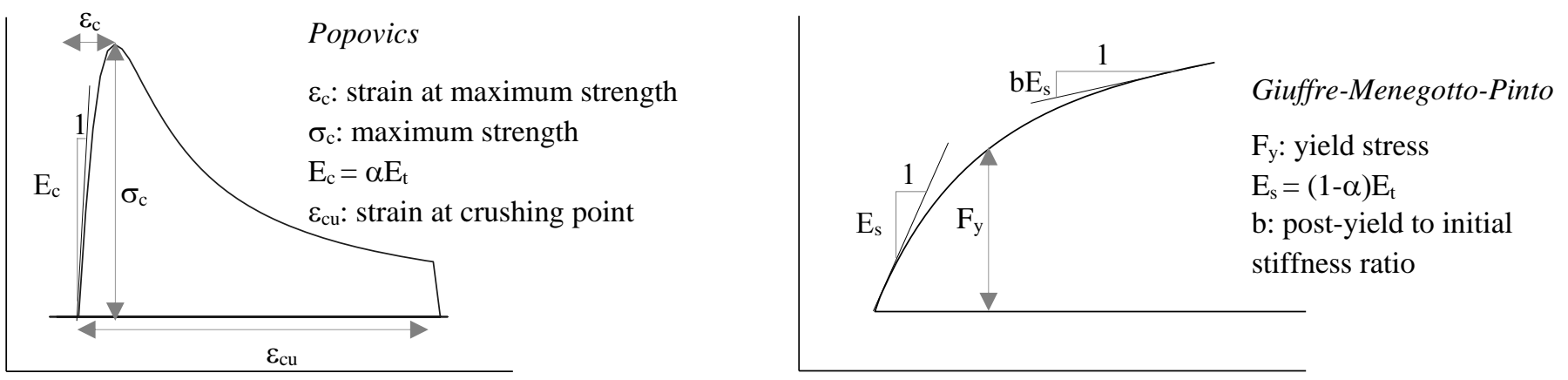

Fig. 4 Stress-strain curves of Popovics (left) and Giuffre-Menegotto-Pinto (right) material models used for generating the first parallel material model 

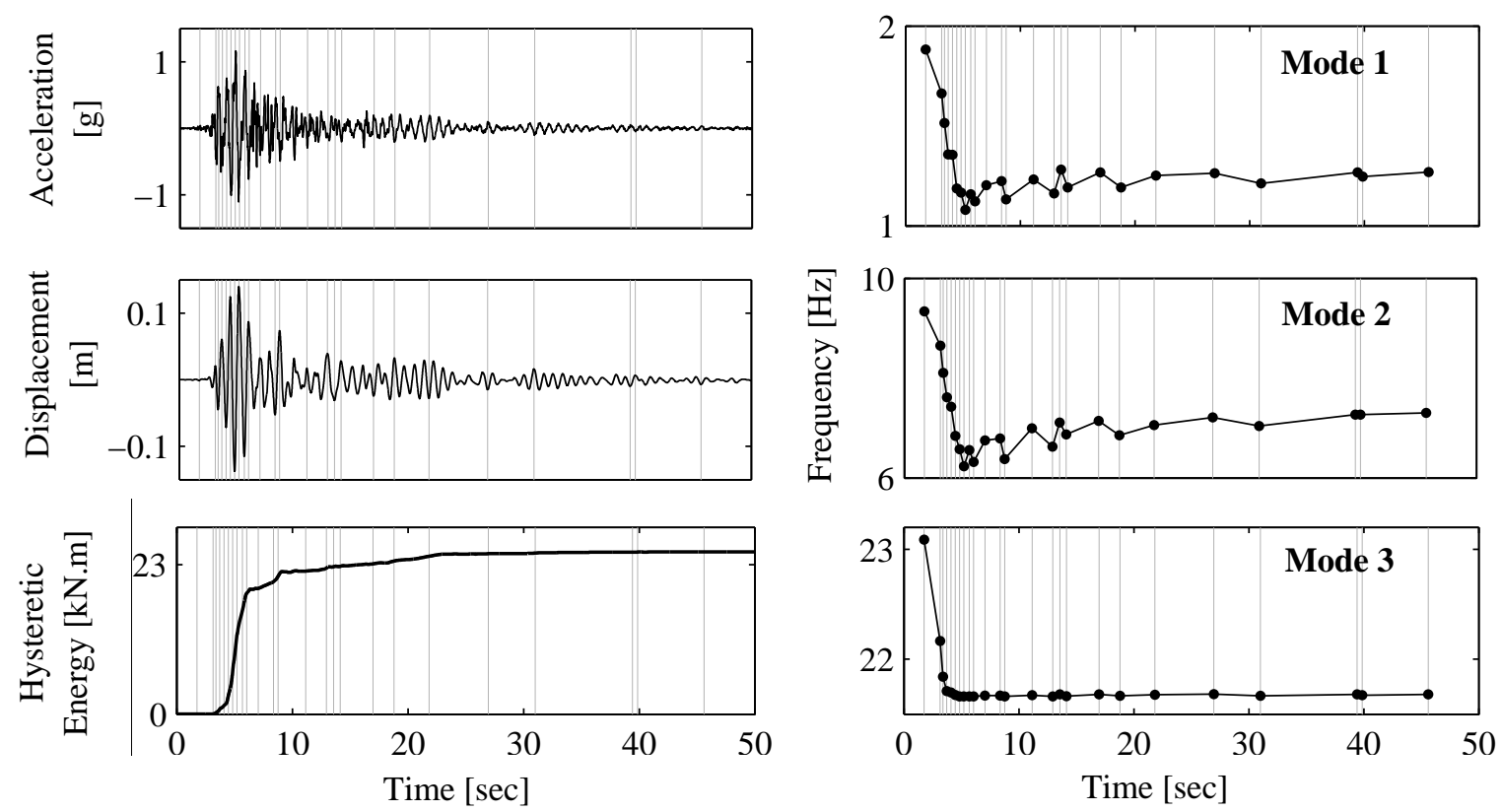

Fig. 5 Time histories of the response features used in the updating process: roof acceleration, roof displacement, first story cumulative hysteretic energy, and time-varying natural frequencies of the first three translational modes during 1994 Northridge earthquake base excitation 

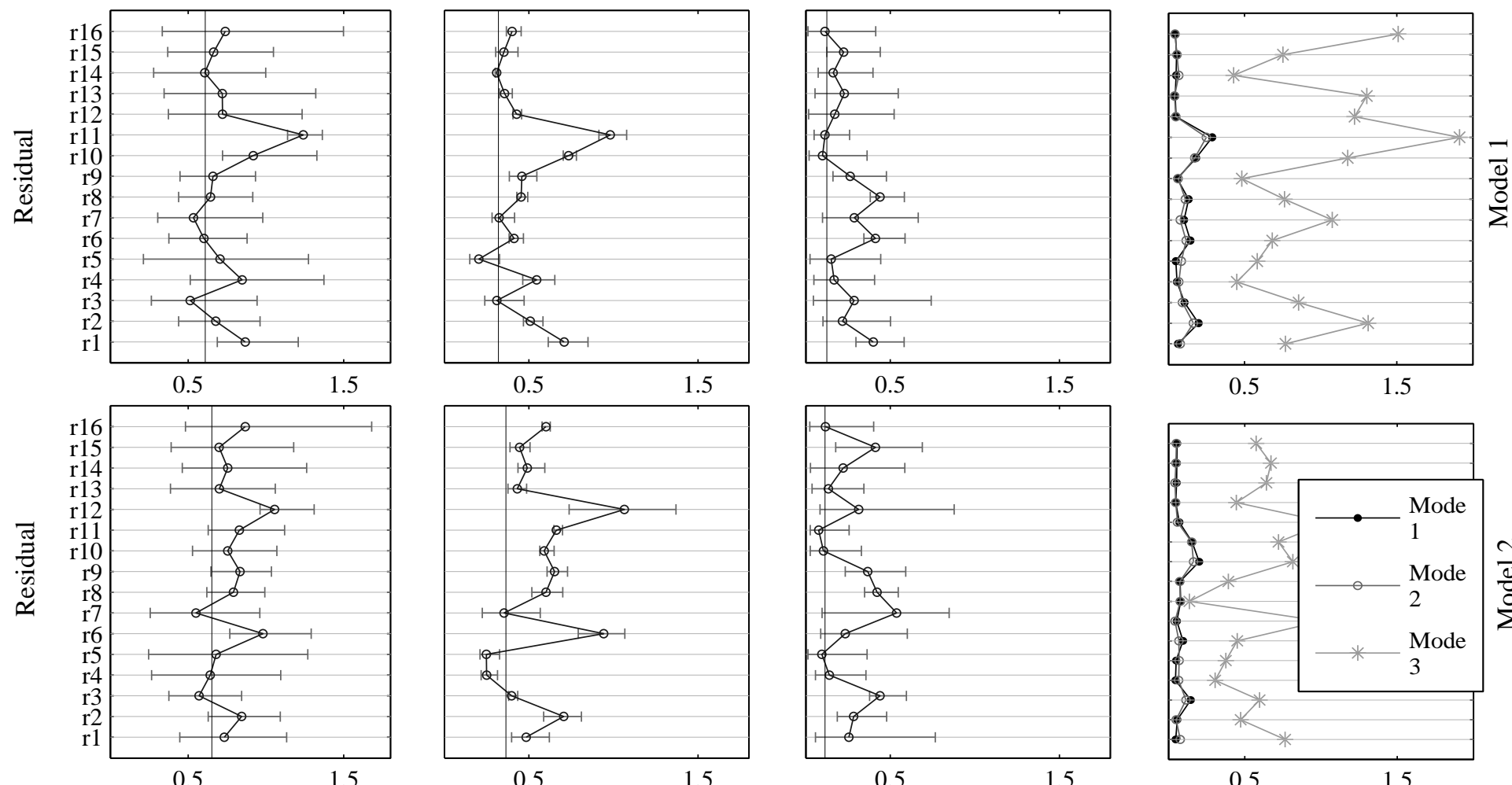

0.5

1.5
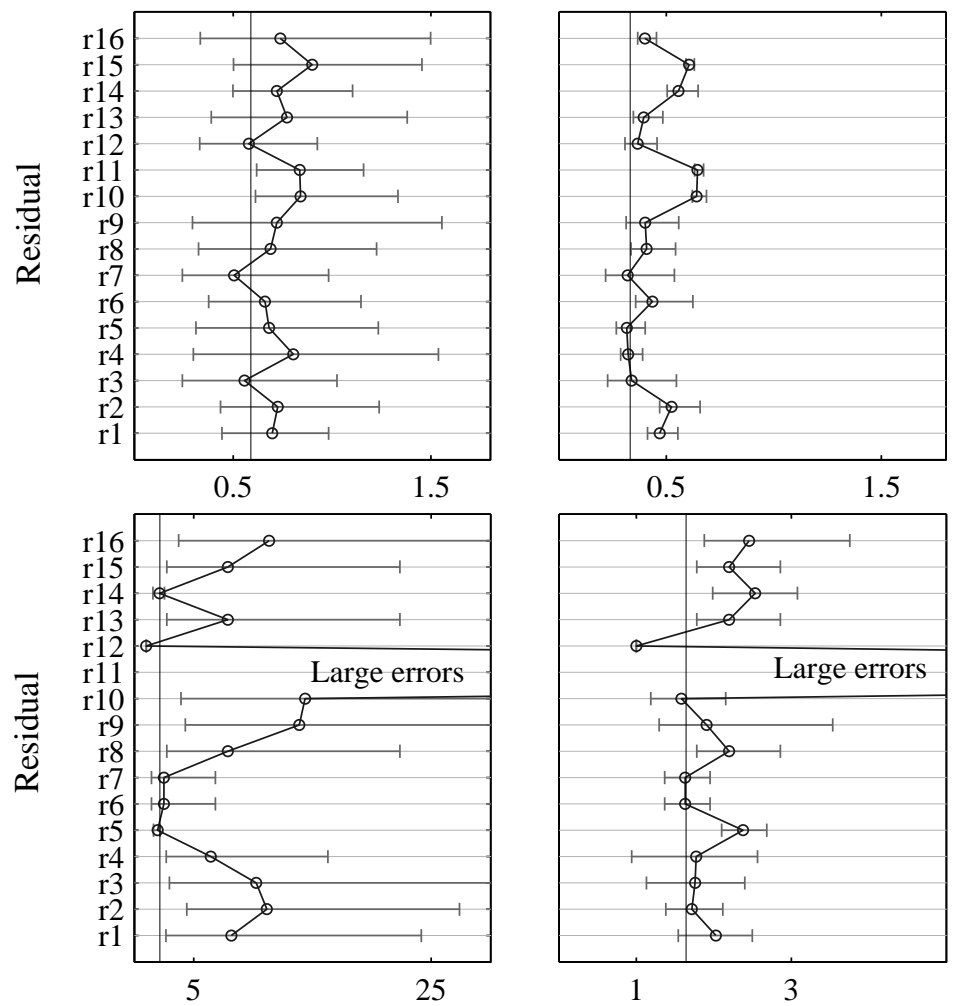

Acceleration Error

Displacement Error

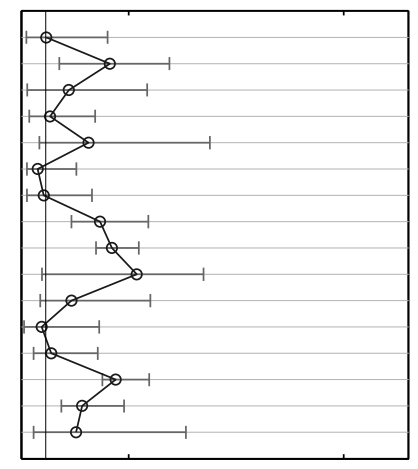

0.5

1.5
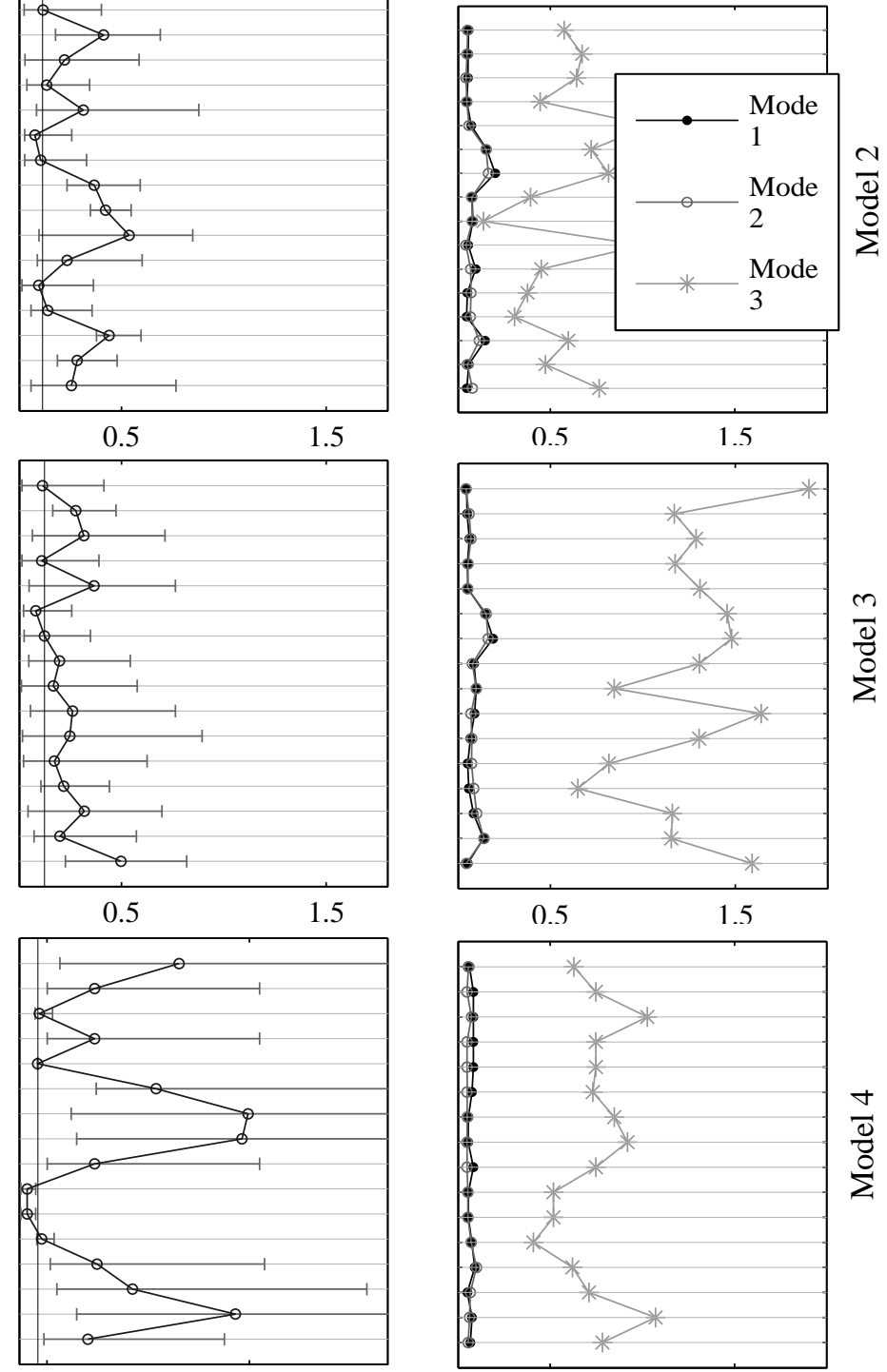

$1.5 \quad 12.5$

Hysteretic Energy Error

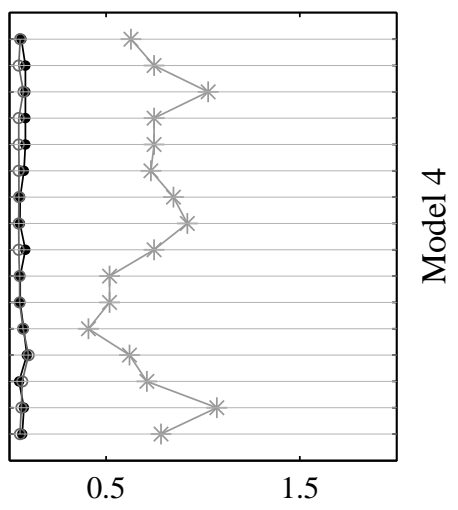

Natural Frequency Error

Fig. 6 Acceleration, displacement, hysteretic energy, and natural frequency error metrics for calibrated models using 16 different residuals and four different material models 

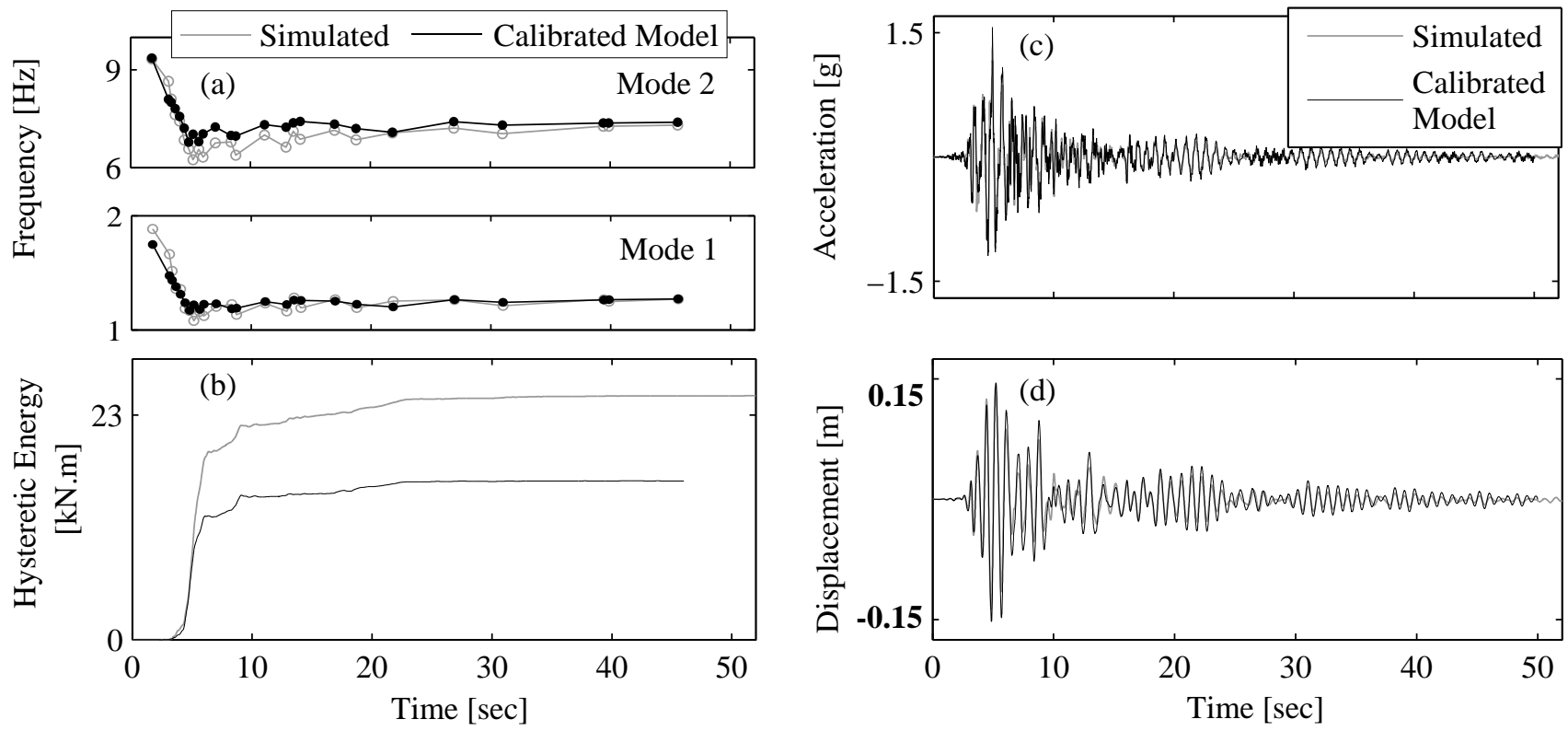

Fig. 7 Comparison of different data features between simulated/measured response and response of a calibrated model using Yassin-Pinto material model and residual r12 (acceleration and frequency) (a) time-varying natural frequencies, (b) hysteretic energy at the first story, (c) roof acceleration, and (d) roof displacement 

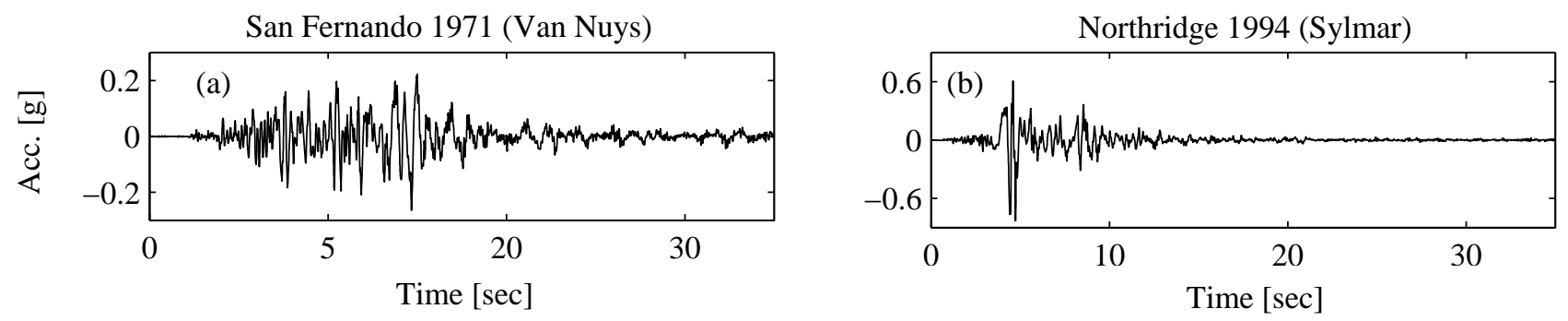

Fig. 8 Acceleration time histories of the two motions used for model validation, (a) San Fernando 1971 recorded at Van Nuys station, and (b) Northridge 1994 recorded at Sylmar station. 

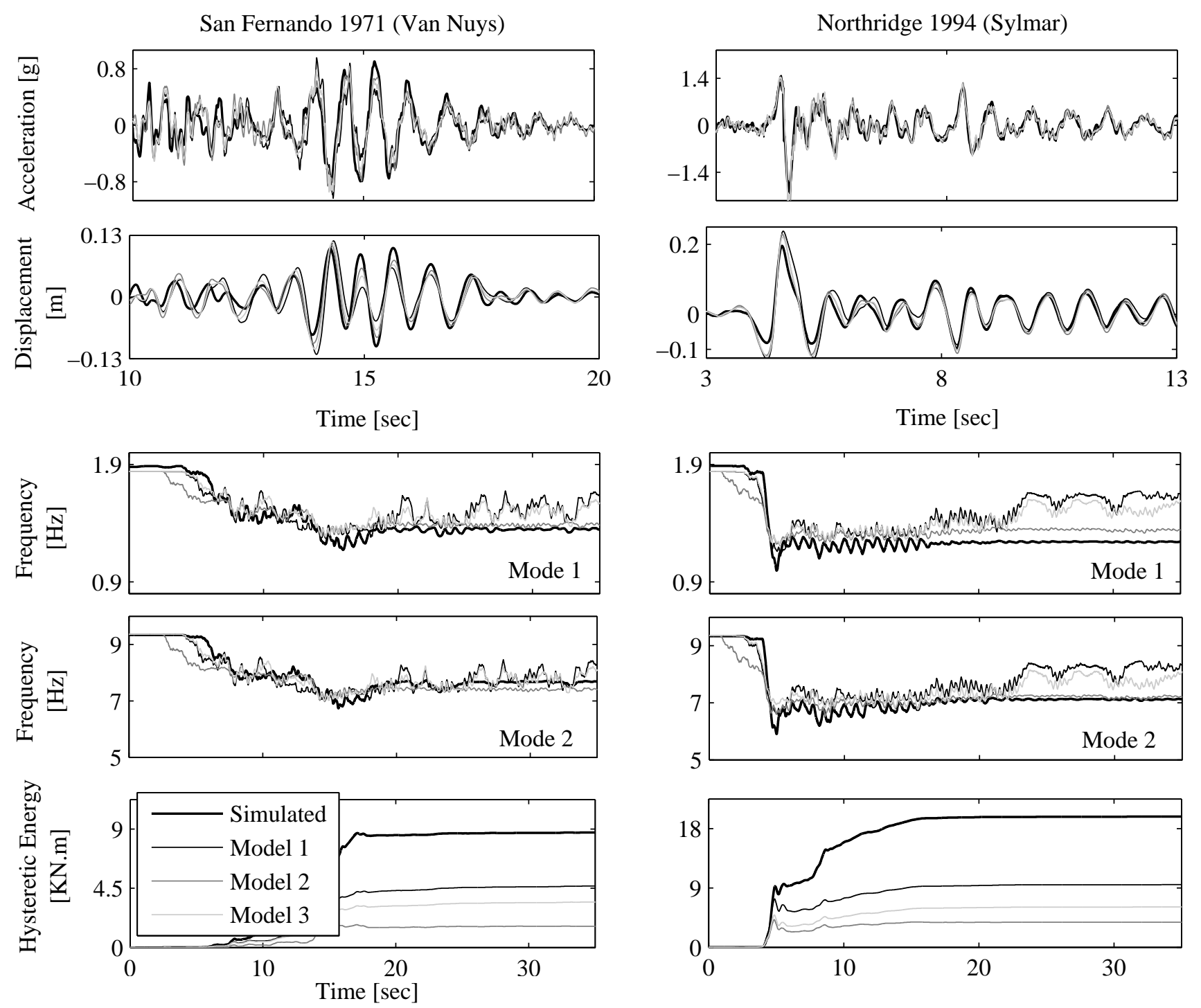

Fig. 9 Predicted structural responses to San Fernando (left column) and Northridge (right column) earthquakes using three calibrated models with material models 1-3 and residual r7 

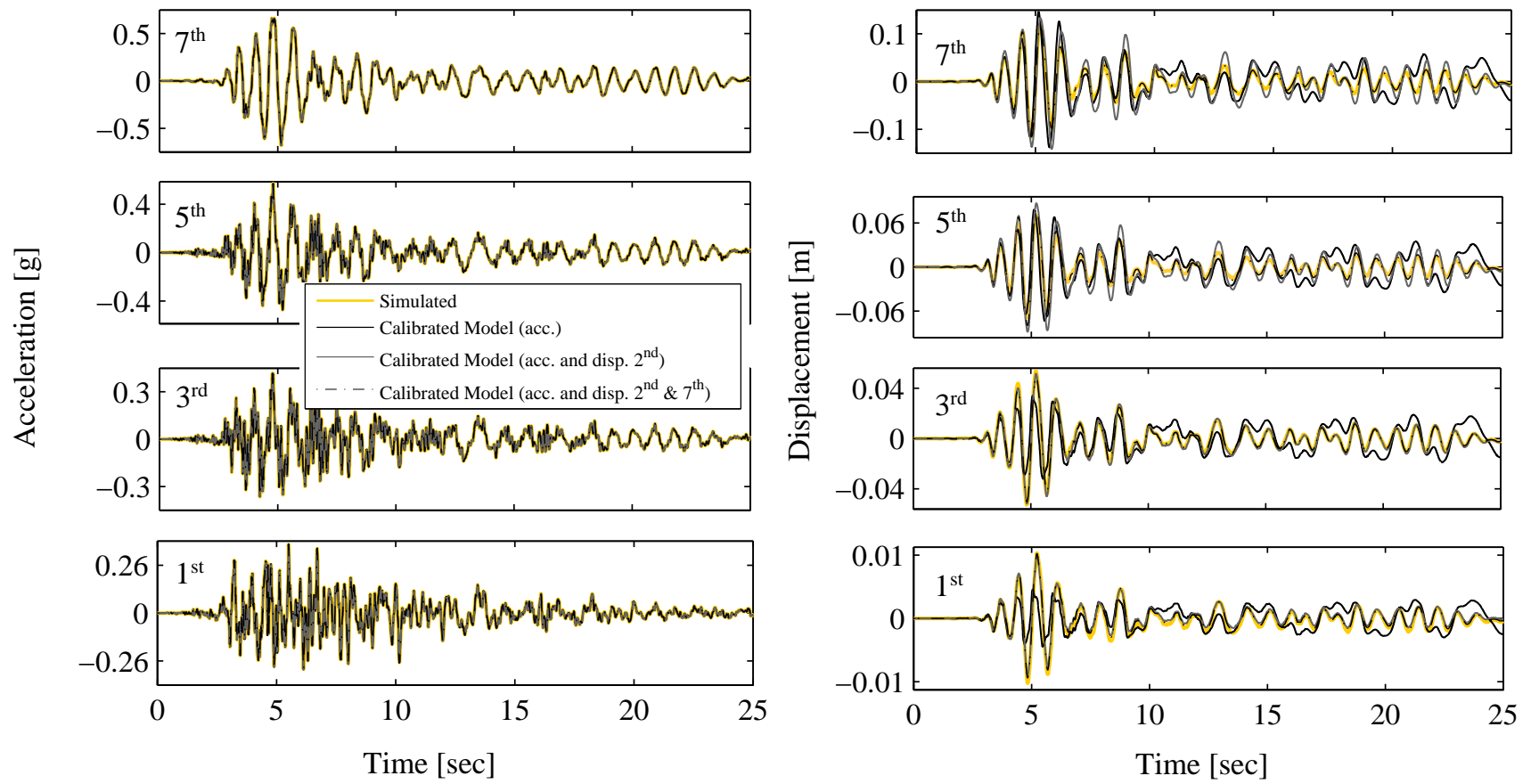

Fig. 10 Predicted acceleration and displacement responses of the cantilever model calibrated using the UKF based on either seven acceleration, seven acceleration and one displacement, or seven acceleration and two displacement channels of data 

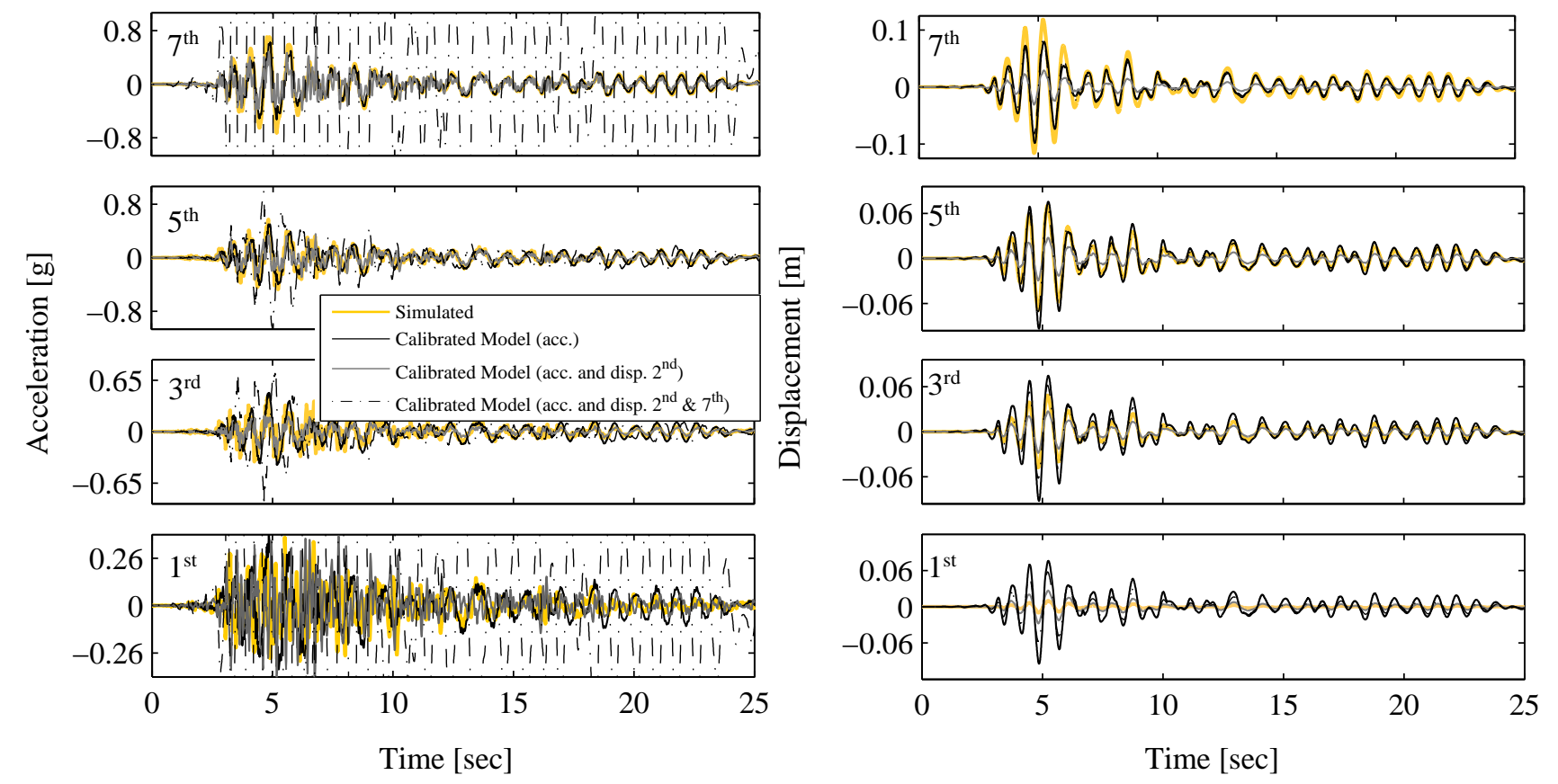

Fig. 11 Predicted acceleration and displacement responses at different floor levels of shear building model calibrated using the UKF based on either seven acceleration, seven acceleration and one displacement, or seven acceleration and two displacement channels of data. 